\title{
Formulation and Evaluation of Acetylsalicylic Acid Suppositories using Capra hircus (Goat) Fat and Its Binary Blends
}

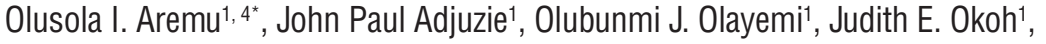 \\ Kokonne E. Ekere ${ }^{1}$, Omolola T. Fatokun², Martins 0. Emeje ${ }^{1,3}$ and Development, Abuja, Nigeria. Development, Abuja, Nigeria. Abuja, Nigeria. \\ 1 Department of Pharmaceutical Technology and Raw Materials Development, National Institute for Pharmaceutical Research \\ 2 Department of Medicinal Plant Research and Traditional Medicine, National Institute for Pharmaceutical Research and \\ 3 Centre for Nanomedicine and Biophysical Drug Delivery, National Institute for Pharmaceutical Research and Development, \\ 4 Department of Pharmaceutics and Industrial Pharmacy, Faculty of Pharmaceutical Sciences, University of Ilorin, Ilorin, Nigeria.
}

\section{ABSTRACT}

A study has been made on the formulation and evaluation of Acetylsalicylic acid (ASA) suppositories using Goat fat (GF) and its binary blends with Palm Kernel oil and Liquid Paraffin.

Cocoa butter was used as the standard reference suppository base. Rectal suppositories containing ASA (300 mg) in pre-calibrated mould were prepared by fusion method and evaluated for appearance, crushing strength, weight variation, melting point, liquefaction time, content uniformity and in-vitro release using standard procedures.

Liquefaction or disintegration time (minutes) followed this order: $\mathrm{ACB}(4.40 \pm 0.84)$ $<\operatorname{AGL}(6.20 \pm 0.83)<\operatorname{AGP}(7.14 \pm 0.84)<\operatorname{AGF}(11.45 \pm 2.20)$ while cumulative drug release (\%) is $\mathrm{AGP}>\mathrm{AGF}>\mathrm{AGL}>\mathrm{ACB}(\mathrm{p}<0.05)$. Results obtained indicated that the bases used generally could be ranked in the order of GL $>$ GP $>$ GF $>\mathrm{CB}(\mathrm{p}<0.05)$ in terms of favourable physicochemical properties investigated.

The foregoing indicates that GL or GP has promising potential and could be a substitute suppository base in the formulation of ASA suppositories.

Keywords: Formulation, Suppositories, Acetylsalicylic acid, Goat fat, Palm Kernel oil

*Corresponding Author: Olusola Aremu, e-mail: solabanks@yahoo.com Olusola Aremu ORCID Number: https://orcid.org/0000-0002-3890-1256 Olubunmi Olayemi ORCID Number: https://orcid.org/0000-0001-5759-7176 Judith Okoh ORCID Number: https://orcid.org/0000-0001-7789-4776 Kokonne Ekere ORCID Number: https://orcid.org/0000-0001-8876-9284 Omolola Fatokun ORCID Number: https://orcid.org/0000-0002-9939-3371 Martins Emeje ORCID Number: https://orcid.org/0000-0002-0202-5426 (Received 15 May 2019, accepted 04 August 2019) 


\section{INTRODUCTION}

Meat production worldwide has been estimated to increase annually by $1.9 \%$ excluding nations like China where meat is not consumed often. ${ }^{1}$ Consequently, the amount of waste or byproducts such as fats obtained from this industry has been increasing. Animal fats are lipid materials that can be obtained from pigs, cows and goats and it has been proven that, the biological source of the fat affects its characteristics ${ }^{2}$; for human health concerns, attention has shifted to the application of these fats in non-food industries such as manufacture of soaps, fatty acids lubricants, feedstuffs, candle waxes and liniments. ${ }^{3}$ They also find wide application in cosmetics, pet food, animal food, biodiesel production and pharmaceutical industry. ${ }^{4,5}$ Pharmaceutical uses of animal fat have been extensively investigated ${ }^{6,7,8,9,10}$ and the findings showed that goat fat is a cheap raw material which is suitable in developing several drug delivery systems. Nnamani et $a l^{11}$ investigated the functional properties of goat fat in topical nano-drug delivery systems and concluded that goat fat is an effective lipid drug carrier. The study by Esimone et $\mathrm{l}^{12}$ demonstrated the effectiveness of goat fat and shea butter in encapsulating benzyl penicillin in liposphere formulations. However, they reported that the presence of goat fat in one of such formulations impacted its stability. Goat fat has also been exploited as a colubricant in tablet formulations and found to improve granule flow and packing into the tablet die resulting in production of compact tablets. ${ }^{13}$ In another study, Momoh et al ${ }^{14}$ investigated the use of goat fat and phospholipids admixture in the formulation of solid-lipid nanoparticles. Their results showed that the drug-loaded nanoparticles improved drug bioavailability and therapeutic activity. In a similar but different study, herbospheres of Vernonia amygdalina prepared by using a lipid matrix containing the combination of goat fat (70 \%) and Phospholipon 9oH (30\%) were observed to be significantly more effective in inhibiting the growth of Staphylococcus aureus than Tetracycline. The emulsifying effect of goat fat has also been reported. ${ }^{15,16,17}$ One study demonstrated the capability of the admixtures of goat fat and melon oil employed in the formulation of self-nanoemulsifying systems (SNEDDS) to deliver indomethacin. ${ }^{18}$

Rectal drug delivery though unconventional, is an apt substitute for oral drug administration, because it circumvents unwanted gastrointestinal (GIT) side effects, reduces hepatic first pass effect and problems relating to drug absorption. They are also beneficial for patients who cannot tolerate oral drugs due to reasons like vomiting or age; particularly the young children. Suppositories are solid medicated formulations designed to be inserted into the rectum where 
they melt, dissolve or disperse and elicit local or systemic effect. Suppository bases are carriers of active medicaments that are incorporated into suppository formulations; they are usually hydrophilic or lipophilic. The bases determine the rate of drug release and absorption from suppository formulations as well as the onset of drug action, as such, appropriate bases are selected for suppository formulations.

Acetylsalicylic acid (ASA) is a non-steroidal anti- inflammatory drug (NSAID) with analgesic, antipyretic, anti-inflammatory and antiplatelet properties. It elicits these effects by inactivating cyclooxygenase enzymes (COX-1 and 2) required for prostaglandin synthesis. ${ }^{19}$ Low dose acetylsalicylic acid irreversibly blocks the formation of thromboxane A2 in platelets, producing an inhibitory effect on platelet aggregation. ${ }^{20}$ Oral NSAIDS like acetylsalicylic acid cause upper and lower GIT disorder such as gastric ulcers due to direct irritation of the gastric mucosa. ${ }^{21}$ As a result of various challenges to oral medication of ASA as enunciated above including problem of emesis in critically ill patient, other dosage forms such as suppository maybe considered to avoid these drawbacks. Therefore, acetylsalicylic acid suppositories will be formulated by using goat fat, goat fat/palm kernel oil (3:1) and goat fat/liquid paraffin (3:1) admixtures and their effects on the physicochemical properties of the suppositories will be compared.

\section{METHODOLOGY}

Materials used include Acetylsalicylic acid powder (Sigma, Germany), Aluminum foil (Novena 85 foil, China), Liquid paraffin (BDH Chemicals ltd, Poole, England), Palm Kernel Oil, Cocoa butter, Hydrochloric acid (EmproveExp Merck, Germany), Goat fat obtained from a batch processed in the laboratory, Distilled water (National Institute for Pharmaceutical Research and Development, Laboratory, Nigeria).

\section{Extraction process}

The goat fat was extracted from its adipose tissue. The extraneous parts of it (adipose tissue) was manually separated and the separated fat thereafter was mashed together by using mortar and pestle. The mashed sample was melted using water bath and filtered through a 250-mesh sieve. The extracted fat was stored in a refrigerator until further use. 


\section{Gas Chromatography-Mass Spectrometry (GC-MS) analysis of Goat fat}

The protocol of Okhale et al, ${ }^{12}$ was adopted in carrying out this analysis. Shimadzu QP-2010 GC with QP-2010 Mass Selective Detector [MSD, operated in the EI mode (electron energy $=70 \mathrm{eV}$ ) was used within the scan range of 45 and $400 \mathrm{amu}$, a scan rate of $3.99 \mathrm{scans} / \mathrm{sec}$, and Shimadzu GCMS solution data system. The Gas chromatography column used was Optima- 5 ms fused silica capillary with $5 \%$ phenyl-methylpolysiloxane stationary phase, with length of $30 \mathrm{~m}, 100$ internal diameter of $0.25 \mathrm{~mm}$ and film thickness of $0.25 \boldsymbol{\mu m}$. The carrier gas was helium with flow rate of $1.61 \mathrm{~mL} / \mathrm{min}$. The program used for Gas chromatography oven temperature was $180^{\circ} \mathrm{C}$ at a rate of $10^{\circ} \mathrm{C} / \mathrm{min}$, then held at $180^{\circ} \mathrm{C}$ for $2 \mathrm{~min}$, followed by $18-280^{\circ} \mathrm{C}$ at a rate of $15{ }^{\circ} \mathrm{C} / \mathrm{min}$, which was again held at $280^{\circ} \mathrm{C}$ for $4 \mathrm{~min}$. The injection port temperature was 250 ${ }^{\circ} \mathrm{C}$ while detector temperature was $280{ }^{\circ} \mathrm{C}$. The goat fat sample was diluted; $1 / 100 \mathrm{v} / \mathrm{v}$ in hexane then $1.0 \boldsymbol{\mu} \mathbf{L}$ was injected using autosampler and in the split mode with ratio of 10:90. Individual constituents of the goat fat were identified by comparing their mass spectra with known compounds and NIST Mass Spectral Library (NIST 11).

\section{Preparation of Acetylsalicylic acid suppositories using different bases}

The bases used were goat fat, goat fat/palm kernel oil (3:1) and goat fat/liquid paraffin (3:1) and cocoa butter. Fusion method was employed in the production of the suppositories in pre-calibrated mould with different bases. Required quantities of the bases were weighed into a beaker and placed in a water bath at about $43^{\circ} \mathrm{C}$ to melt. Acetylsalicylic acid was weighed into a beaker (30omg per suppository); portion of melted base was mixed with the drug and then the required amount of base was added and the content of the beaker was stirred at about $39^{\circ} \mathrm{C}$ by using a magnetic stirrer until homogenous. The mixture was poured into the mould cavities until overflowed; the cavities were filled with the melted base as the solidifying mixture was shrinking. The mould content was allowed to solidify after which the mould was unscrewed. The suppositories were removed and wrapped in aluminum foils until further analysis was carried out.

\section{Evaluation of Suppositories}

\section{Appearance (visual characterization)}

Ten randomly selected suppositories (from each batch) were examined as a whole and also after splitting them longitudinally; the colour, odour, shape as 
well as presence or absence of fissuring, pitting, exudation, sedimentation and migration of active ingredients were assessed.

\section{Weight variation}

The weight variation test was carried out according to British Pharmacopoeia. ${ }^{22}$ Twenty suppositories were randomly selected from each batch of the formulations, weighed individually using an analytical balance (Mettler Toledo, Switzerland), the mean weights and standard deviations were calculated.

\section{Hardness/Crushing test}

The crushing strength, a measure of mechanical strength or hardness of the suppository was determined using the hardness tester (Erweka GmbH Germany). Three suppositories were randomly selected from each batch. The force under which each suppository cracked was recorded.

\section{Liquefaction time}

From each batch, one suppository was placed in a beaker with a thermometer inserted and placed in a thermo regulated heating mantle to maintain the temperature at $39 \pm 1^{\circ} \mathrm{C}$. The time taken for the suppository to completely melt was recorded as the liquefaction time. Three suppositories from each batch were evaluated for this purpose.

\section{Melting point determination}

The melting point of the suppositories was determined according to method reported by Adebayo and Akala ${ }^{23}$. -Briefly, a suppository, randomly selected from each batch, was placed in a beaker with a thermometer inserted. The beaker was placed on a water bath and regulated to a gradual temperature increase of $1^{\circ} \mathrm{C} / 2 \mathrm{~min}$. The temperature at which the suppository sample began to melt was taken as the melting point. The results obtained were average of quintuplicate determinations.

\section{Content uniformity}

The method of Setnikar and Fontani ${ }^{24}$ was adopted with some modifications. Three suppositories were randomly selected from each batch and assayed for drug content individually. The suppository was placed in a beaker containing $60 \mathrm{~mL}$ of $0.1 \mathrm{~N} \mathrm{HCl}$ solution that was pre-heated to and maintained at $37 \pm 1^{\circ} \mathrm{C}$. The suppository was allowed to melt. The mixture was made up to $100 \mathrm{~mL}$ and then stirred at 100 rpm for 5 minutes using magnetic stirrer and filtered through a cotton plug. This volume was essential to allow for sink condition in order that the required amount of drug may be released from the product into 
the medium. The absorbance of $5 \mathrm{~mL}$ of filtrate was measured using UV-Vis spectrophotometer (Jenway 6505, UK) at $230 \mathrm{~nm}$. The concentration of the acetylsalicylic acid in the solution was calculated using a standard Beer- Lambert curve obtained from the plot of absorbance against several dilute concentrations ranging from $2 \times 10-5$ to $5 \times 102 \mu \mathrm{g} / \mathrm{mL}$ as shown in Figure 1 .

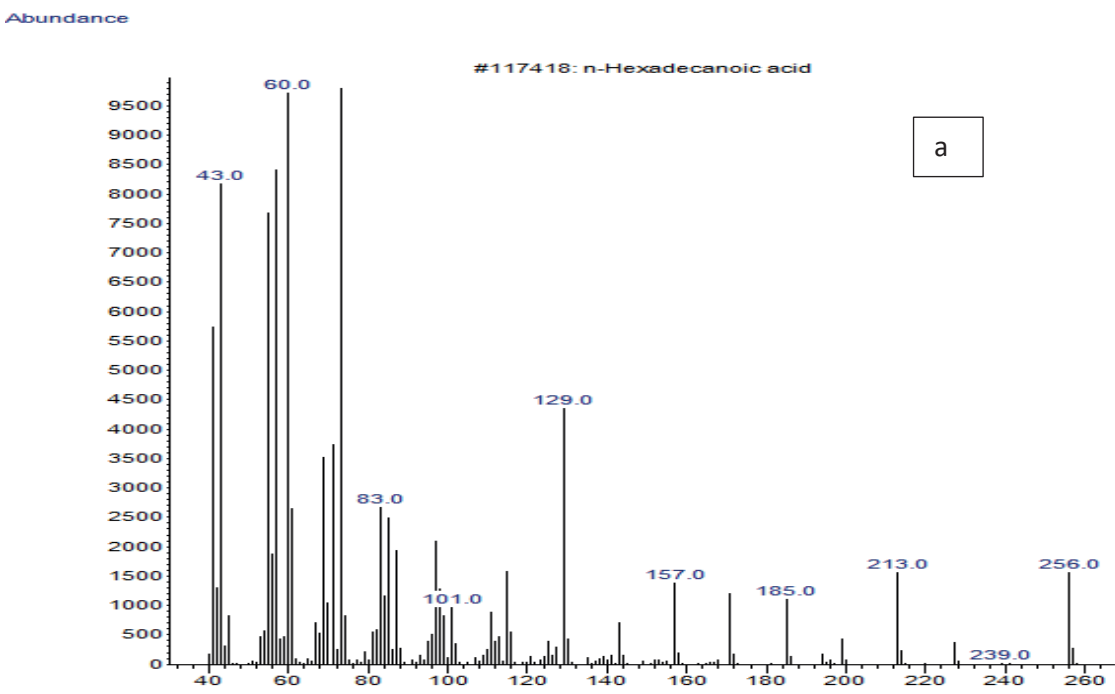

Abundance

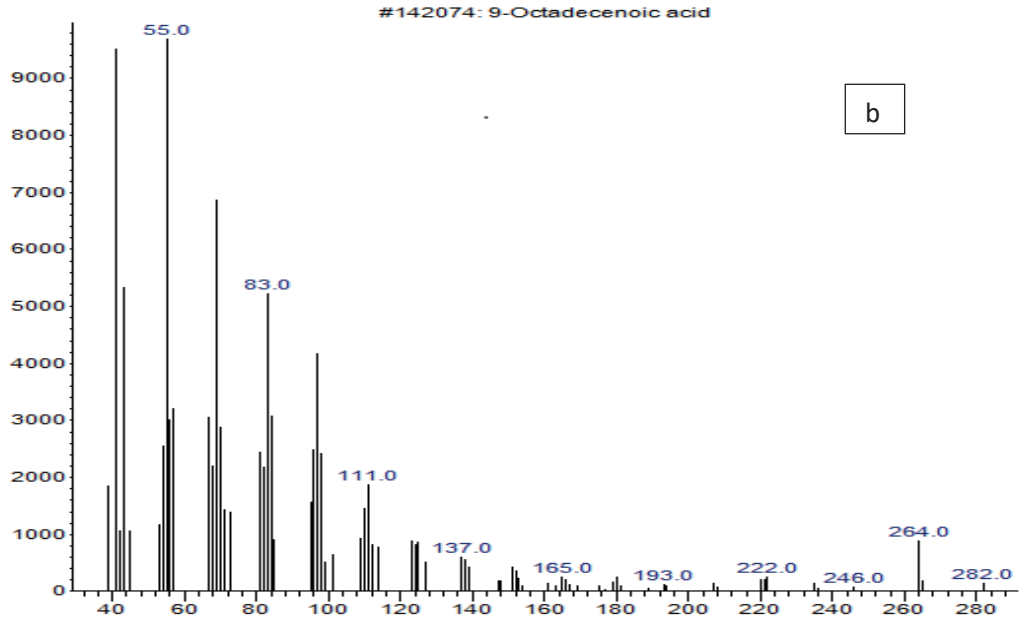

$m v z \rightarrow$

Figure 1. Gas chromatography spectra of goat fat showing the saturated fatty acids (a) hexadecanoic acid and (b) octadecanoic acid. 


\section{Release studies}

The release studies were carried out using a magnetic stirrer assembly. A 100 $\mathrm{mL}$ quantity of $0.1 \mathrm{~N} \mathrm{HCl}$ solution was maintained on the magnetic stirrer assembly at temperature of $37 \pm 1^{\circ} \mathrm{C}$. One suppository from each batch was placed in the solution and the magnetic stirrer was set at $50 \mathrm{rpm} .5 \mathrm{~mL}$ portion of the release medium was withdrawn at an interval of 5 minutes and was filtered through a cotton plug. The volume of the release medium was kept constant by replacing the amount withdrawn with $0.1 \mathrm{~N} \mathrm{HCl}$ after each withdrawal. Absorbance of $5 \mathrm{~mL}$ of filtered portions was determined using UV-Vis spectrophotometer (Jenway 6505, UK) at $230 \mathrm{~nm}$.

\section{RESULTS AND DISCUSSION}

Gas Chromatography (GC)/Mass Spectroscopy (MS) has long been used for the selective qualitative and quantitative analysis of non-polar compounds particularly fatty acids with long chain alkyl groups. The detection of structural molecular ions generated from the MS source provides more sensitive and selective assay of varied arrays of fatty acids present in lipid samples. ${ }^{25}$ The GC-MS spectra in Figure 1 shows that goat fat contains mainly long chain fatty acids and methyl esters; chiefly cis-vaccenic acid (52.29\%), saturated fatty acids such as octadecanoic acid (38.26 \%), hexadecanoic acid also known as palmitic acid (8.46\%) and alcohols. Vaccenic acid (VA) is a positional and geometric isomer of oleic acid, and is reported as the predominant trans-isomer in ruminant fats. The chemical and physical stability, non-reactive and widely compatible properties of these fatty acids confer on goat fat the properties of a good suppository base. The outcome of various physicochemical assessments carried out on the suppositories is presented in Table 1. The goat fat extracted was off white coloured solid with characteristic odour. The formulated suppositories were solid at room temperature and assessed to be consistent in appearance with no air bubbles. The dissected suppositories have no holes or were not brittle and as such were not fragile. This implies that they could withstand transportation and other mechanical stresses they may be exposed to. ${ }^{26}$ 
Table 1. Suppository formulations and their composition

\begin{tabular}{|c|c|c|c|c|}
\hline Ingredients & AGF & AGL & AGP & ACB \\
\hline $\begin{array}{c}\text { Acetyl salicylic } \\
\text { acid }\end{array}$ & $0.30 \mathrm{~g}$ & $0.30 \mathrm{~g}$ & $0.30 \mathrm{~g}$ & $0.30 \mathrm{~g}$ \\
\hline Goat fat to & $39.35 \mathrm{~g}$ & - & - & - \\
\hline $\begin{array}{c}\text { Goat fat + Liquid } \\
\text { paraffin (3:1) to }\end{array}$ & - & 37.44 & - & - \\
\hline $\begin{array}{c}\text { Goat fat + Palm } \\
\text { kernel oil (3:1) } \\
\text { to }\end{array}$ & - & - & 39.10 & - \\
\hline \begin{tabular}{c} 
Cocoa butter to \\
\hline
\end{tabular} & - & - & - & 39.80 \\
\hline
\end{tabular}

AGF= acetylsalicylic acid + goat fat, $A G L=$ acetylsalicylic acid + Goat fat/ liquid paraffin (3:1), $\mathrm{AGP}=$ acetylsalicylic acid + goat fat/palm kernel oil (3:1), $\mathrm{ACB}=$ acetylsalicylic acid + cocoa butter

The physicochemical properties of the suppositories that are presented in Table 2 shows that all of the suppositories conform to BP requirement for weight uniformity. Not more than two individual suppositories deviated from the average weight by more than $5 \%$ and no suppository differed from the average weight by more than $10 \% .{ }^{22}$ The relative standard deviations (RSD) of the mean weight of the suppositories were less than $3.5 \%$. Results of the crushing strength shows that, there were significant $(\mathrm{p}<0.05)$ differences between the values obtained for the suppositories and the placebo; with the order of strength being Goat fat alone; GF $(3.43 \mathrm{~N})>$ Goat fat and liquid paraffin; GL $(3.11 N)>$ Goat fat and Palm kernel oil; GP (2.39N) and Goat fat + Acetylsalicylic acid; AGF $(8.01 \mathrm{~N})>$ Goat fat and liquid paraffin + Acetylsalicylic acid AGL $(6.54 \mathrm{~N})>$ Goat fat and palm kernel oil + Acetylsalicylic acid; AGP (3.27N) for placebo and medicated suppositories respectively. Although there is no official requirement as regards the acceptable values for the crushing strength of suppositories, it is nonetheless recognized that, crushing strength helps in identifying the mechanical strength of suppositories during handling, packaging and shipping. The mechanical strength can be valuable to avoid problems with formulations in which the melting point has been depressed by inclusion of either active pharmaceutical ingredient or an adjuvant. 
Table 2. Physicochemical parameters of the suppositories

\begin{tabular}{|c|c|c|c|c|c|c|c|c|}
\hline $\begin{array}{c}\text { Physicochemical } \\
\text { parameters }\end{array}$ & AGF & GF & AGL & GL & AGP & GP & ACB & CB \\
\hline Shape & Torpedo & Torpedo & Torpedo & Torpedo & Torpedo & Torpedo & Torpedo & Torpedo \\
\hline Colour & White & Off-white & Off-white & Off-white & Off-white & Ash & $\begin{array}{c}\text { Light } \\
\text { yellow }\end{array}$ & $\begin{array}{c}\text { Light } \\
\text { yellow }\end{array}$ \\
\hline Mean weight (g) & $2.05 \pm 0.03$ & - & $2.01 \pm 0.02$ & - & $2.02 \pm 0.02$ & - & $2.01 \pm 0.01$ & - \\
\hline Hardness (N) & $8.01 \pm 0.28$ & $3.48 \pm 0.85$ & $6.54 \pm 0.57$ & $6.11 \pm 0.28$ & $3.27 \pm 0.57$ & $2.39 \pm 0.39$ & - & - \\
\hline \begin{tabular}{c} 
Melting point ( $\left.{ }^{\circ} \mathrm{C}\right)$ \\
\hline Liquefaction time \\
(min)
\end{tabular} & $36.70 \pm 0.06$ & $38.30 \pm 0.03$ & $38.20 \pm 0.36$ & $38.30 \pm 0.70$ & $37.30 \pm 0.15$ & $36.60 \pm 0.76$ & $31.00 \pm 0.61$ & $30.10 \pm 0.71$ \\
\hline \begin{tabular}{c} 
Displacement value \\
\hline
\end{tabular} & $1.35 \pm 2.20$ & $14.47 \pm 2.10$ & $6.20 \pm 0.83$ & $6.25 \pm 2.30$ & $7.14 \pm 0.84$ & $7.11 \pm 0.64$ & $4.40 \pm 0.84$ & $3.20 \pm 0.63$ \\
\hline
\end{tabular}

AGF= Acetylsalicylic acid + Goat fat; GF= Goat fat, $A G L=$ Acetylsalicylic acid + Goat fat/Liquid Paraffin (3:1); GL= Goat fat/Liquid Paraffin (3:1); AGP= Acetylsalicylic acid + Goat fat/Palm kernel oil (3:1); GP= Goat fat/Palm kernel oil (3:1); ACB= Acetylsalicylic acid + Cocoa butter; $\mathrm{CB}=$ Cocoa butter

Acceptable or "good" crushing strength values are suggested to be in the range between 17.7 and $19.6 \mathrm{~N}$; although the results obtained from this present study are not within this range, it was noted that, throughout the period of this study, the suppositories remained non-brittle and solid at room temperature except for those that were formulated with cocoa butter. This suggest that they can withstand the mechanical rigours of handling and transportation. The inclusion of acetylsalicylic acid increased the crushing strengths of the suppositories, probably because of its high concentration (300mg) in the bases. However, crushing strength of formulations with cocoa butter could not be determined due to its instability during production. It is a known fact that cocoa butter could exist in different polymorphic forms depending on the exposure to varying temperature conditions. The melting points of AGF, AGL and AGP are $36.7,38.2$ and $37.3^{\circ} \mathrm{C}$ respectively (Table 2 ).

These values fall within the acceptable range for suppository formulations. The melting points of AGF was observed to be lower than its respective placebo base which is $38.3^{\circ} \mathrm{C}$ while that of AGL and AGP are higher than their respective placebo bases, 37.3 and $36.6{ }^{\circ} \mathrm{C}$ respectively. The change in temperature is probably as result of the inclusion of the active ingredient which may affect 
the release of the drug.27 The melting point of cocoa butter with the drug is $31^{\circ} \mathrm{C}$ as shown in Table 2; this is low for storage in tropic conditions. The liquefaction times for all suppositories showed significant $(\mathrm{p}<0.05)$ difference with an order of AGF (11.45 \pm 2.20$)>$ AGP (7.14 \pm 0.84$)>A G L ~(6.20 \pm 0.83)$; however all of these values fall within the acceptable limits as suggested by Saho $0^{28}$ which says that liquefaction time influences drug absorption after release and subsequently influences the time it takes for the drug to reach peak plasma concentration.

Invariably there is a better patient compliance unlike when there is a prolonged liquefaction time. On the other hand, a suppository that takes a longer time to liquefy may exert irritant action on the rectal mucosa and as such increase release time and delay onset of action. Drug content of all the suppositories was computed from the calibration curve given in Figure 2.

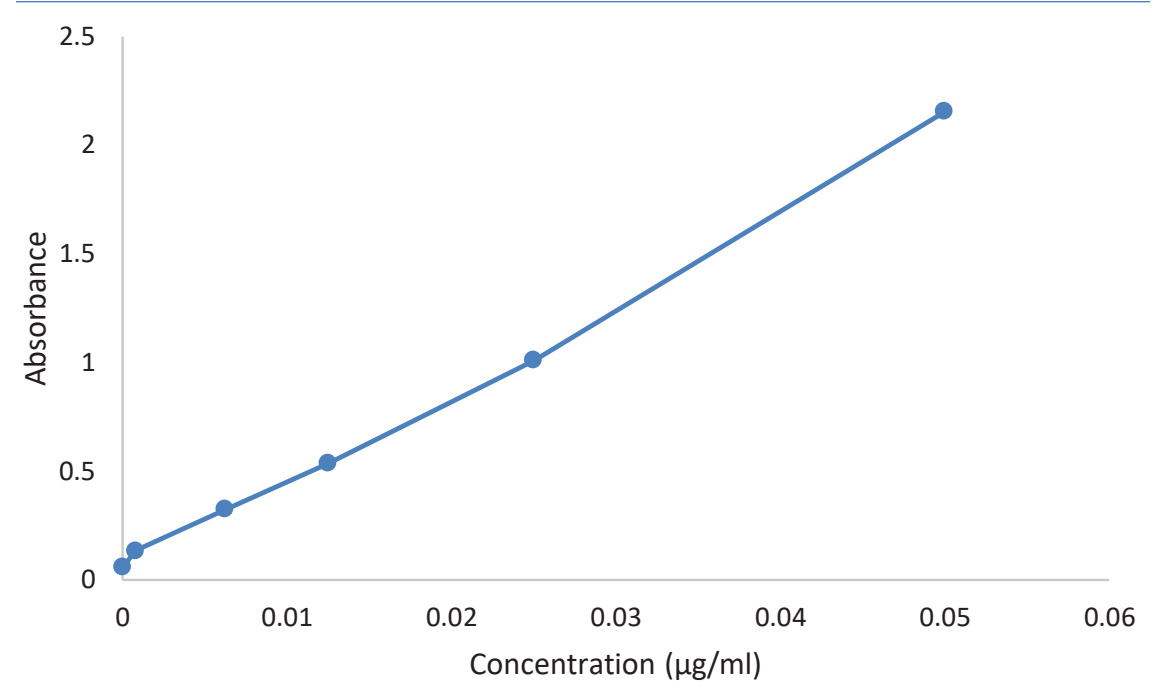

Figure 2. Calibration curve of Acetyl salicylic acid in $0.1 \mathrm{~N} \mathrm{HCl}$

The mean drug content for AGF and AGL suppositories met the USP requirement for the content uniformity. The mean drug content of these two batches fall within (96.7- 99.2\%) as seen in Figure 3. This is an indication of even dispersion of active ingredient in the base. In some other instances inconsistency in active ingredient content in suppositories is usually due to the improper mixing of the molten bases or due to sedimentation of the drug by gravity during production. ${ }^{29}$ This factor may account for why AGP and ACB mean drug content of 84.5 and $94.6 \%$ respectively was outside the acceptable range. The 
most important thing is to realize that for the patient, the release characteristics are the determining properties towards the therapeutic success. What must be targeted is an optimal bioavailability which for the formulator means ensuring optimal and reproducible release in vitro/in vivo. As can be seen in Figure 4, there is no significant difference $(\mathrm{p}<0.05)$ in the rate and extent of release of the medicament from AGP, AGL and AGF. It can be concluded that there is little or no affinity between the bases and the medicament. Barring other physiological conditions of the rectum, there is relative assurance that the drug will be available biologically to elicit its action. The case is different for ACB (Figure 4); where the rate and extent of release was the least of all the bases interrogated in this study. It goes to suggest that, there might be some level of affinity between the drug and this base.

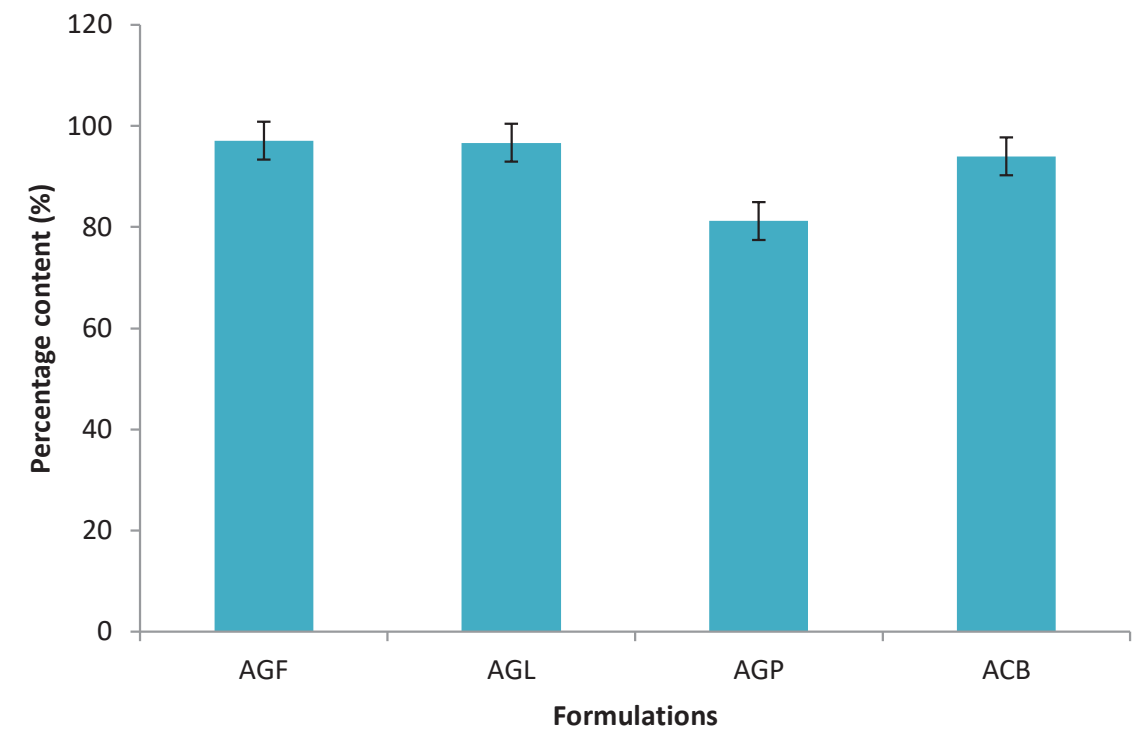

Key: AGF= Acetylsalicylic acid + Goat fat; AGL = Acetylsalicylic acid + Goat fat/Liquid paraffin (3:1); AGP= Acetylsalicylic acid + Goat fat/Palm kernel oil (3:1); ACB= Acetylsalicylic acid + Cocoa butter

Figure 3. Percentage content of acetylsalicylic acid suppositories 


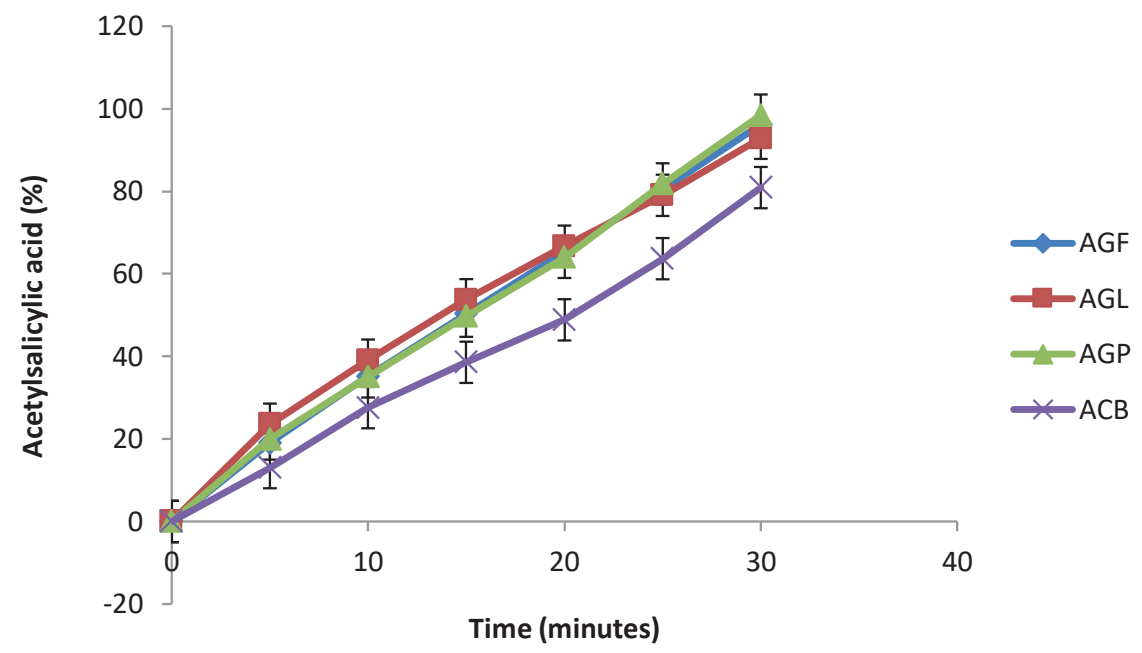

AGF= Acetylsalicylic acid + goat fat; AGL= Acetylsalicylic acid + Goat fat/ Liquid Paraffin (3:1); AGP= Acetylsalicylic acid + Goat fat/Palm kernel oil (3:1); ACB= Acetylsalicylic acid + Cocoa butter

Figure 4. Release profile of Acetylsalicylic acid suppositories

Drug release kinetics studies were analyzed using Zero-order, First-order and Higuchi release models as shown in Table 3. Adjusted Coefficient of Determination ( $\mathrm{R}$ adjusted) was used in selecting the best-fit release method. AGF (R2=0.999), AGL (R2=0.998), AGP (R2=0.998) and ACB (R2=0.993) were found to follow Zero-order model. AGL $(\mathrm{R} 2=0.992)$ fitted also perfectly on Higuchi model.

The release mechanism of acetylsalicylic acid from the suppositories was analyzed with Korsmeyer-peppas model. The release exponents, n, for all the formulations range from 0.76 to 0.98 . These values of 'n' for all the formulations were greater than 0.5 suggesting non-Fickian diffusion mechanisms of drug release from the suppositories. It indicates that the release of drug from the bases involves melting of the base and partitioning of the drug between the molten base and the dissolution medium. Non-Fickian diffusion mechanism is able to ensure better release of the medicament, faster absorption and timely onset of action. 
Table 3. Release rate constant and model fitting parameters for release kinetics of different Acetylsalicylic acid suppository formulations

\begin{tabular}{|c|c|c|c|c|c|}
\hline $\begin{array}{l}\text { Release } \\
\text { Kinetic } \\
\text { models }\end{array}$ & $\begin{array}{l}\text { Selection } \\
\text { parameters }\end{array}$ & AGF & AGL & AGP & ACB \\
\hline \multirow[t]{2}{*}{ Zero order } & $\mathrm{K}_{0}(\min )$ & 3.068 & 2.737 & 3.145 & 2.616 \\
\hline & $\mathrm{R}^{2}$ & 0.999 & 0.998 & 0.998 & 0.992 \\
\hline \multirow[t]{2}{*}{ First order } & $\mathrm{K}_{1}(\mathrm{mg} / \mathrm{min})$ & 0.027 & 0.023 & 0.027 & 0.029 \\
\hline & $\mathrm{R}^{2}$ & 0.943 & 0.945 & 0.959 & 0.939 \\
\hline \multirow[t]{2}{*}{ Higuchi } & $\mathrm{K}_{\mathrm{H}}\left(\mathrm{mg} / \mathrm{min}^{-1 / 2}\right)$ & 23.70 & 21.23 & 24.03 & 20.09 \\
\hline & $\mathrm{R}^{2}$ & 0.986 & 0.992 & 0.976 & 0.967 \\
\hline \multirow[t]{2}{*}{$\begin{array}{c}\text { Korsmeyer- } \\
\text { Peppas }\end{array}$} & $\mathrm{K}_{\mathrm{KP}}\left(\mathrm{mg} / \mathrm{min}^{\mathrm{n}}\right)$ & 0.901 & 0.762 & 0.885 & 0.986 \\
\hline & $\mathrm{R}^{2}$ & 0.999 & 0.999 & 0.997 & 0.996 \\
\hline
\end{tabular}

AGF= Acetylsalicylic acid + Goat fat; AGL= Acetylsalicylic acid + Goat fat/ Liquid paraffin (3:1); AGP = Acetylsalicylic acid + Goat fat/Palm kernel oil (3:1); ACB= Acetylsalicylic acid + Cocoa butter

From the results of this study, Acetylsalicylic acid suppositories were successfully prepared using single and binary blends of goat fat with palm kernel oil, liquid paraffin and cocoa butter. Any of the blends; goat fat and liquid paraffin or goat fat and palm kernel oil, may be a very good substitute to the more expensive bases used in formulation of suppositories. The in vivo performance tests of the optimized formulations is ongoing in our laboratory and will form a separate report.

The Acetylsalicylic acid suppositories prepared using single and binary blends of goat fat with palm kernel oil, liquid paraffin and cocoa butter showed that, any of the two blends may be a very good substitute to the more expensive bases. The in vivo performance of the optimized formulations is ongoing in our laboratory and will form a separate report.

\section{CONFLICT OF INTEREST}

The authors declare no conflict of interest.

\section{ACKNOWLEDGEMENT}

The authors are grateful to the technical staff in the Department of Pharmaceutical Technology and Raw Materials Development, National Institute for Pharmaceutical Research and Development (NIPRD), Abuja, Nigeria for their input in the course of this work. 


\section{REFERENCES}

1. Food and Agriculture Organization (FAO). Food Outlook; Biannual Report on Global Food Markets; Food and Agriculture Organization of the United Nations: Rome, Italy, 2017; pp. 1-142.

2. National Research Council. Fat Content and Composition of Animal Products. Washington, DC: Printing and Publishing Office, National Academy of Science, 1976; pp 203.

3. Food and Agriculture Organization. Definition and classification of commodities: 14 vegetable and animal oils and fats. 1994; http://www.fao.org/waicent/faoinfo/economic/faodef/ fdef14e.htm.

4. Rivera, J. A.; Sebranek, J. G.; Rust, R. E.; Tabatabai, L. B. Composition and Protein Fractions of Different Meat By-Products Used for Pet Food Compared with Mechanically Separated Chicken (MSC). Meat Sci. 2ooo, 55, 53-59.

5. Gokul, R. S.; Ranjitha, J. Comprehensive Study on Biodiesel Produced from Waste Animal Fats-A Review. J. Environ. Sci. \& Tech. 2018, 11, 157-166.

6. Attama, A. A.; Nkemnele, M. O. In Vitro Evaluation of Drug Release from Self Micro-Emulsifying Drug Delivery Systems Using a Novel Biodegradable Homolipid from Capra hircus. Int. J. Pharm. 2005, 304, 4-10.

7. Attama, A. A.; Muller-Goymann, C. C. A Critical Study of Novel Physically Structured Lipid Matrices Composed of a Homolipid from Capra hircus and Theobroma Oil. Int. J. Pharm. 2006, 322, 67-78.

8. Attama, A. A.; Schicke, B. C.; Paepenmuller, T.; Muller-Goymann, C. C. Solid Lipid Nanodispersions Containing Mixed Lipid Core and a Polar Heterolipid: Characterization. Eur. J. Pharm. \& Biopharm. 2007, 67, 48-57.

9. Attama, A. A.; Muller-Goymann, C. C. Effect of Beeswax Modification on the Lipid Matrix and Solid Lipid Nanoparticle Crystallinity. Colloids Surf. A Physicochem. Eng. Asp. 2008, 315, 189-195.

10. Attama, A. A.; Igbonekwu, C. N. In Vitro Properties of Surface-Modified Solid Lipid Microspheres Containing an Antimalarial Drug: Halofantrine. Asian Pac. J. Trop. Med. 2011, 4, 253-258.

11. Nnamani, P. O.; Ibezim, E. C.; Attama, A. A.; Adikwu, M. U. Piroxicam-Loaded Pgogylated Tallow Fat-Based Solid Lipid Microparticles: Characterization and in vivo evaluation. Nig. J. Pharm. Res. 2010, 8, 19-35.

12. Esimone, C. O.; Attama, A. A.; Osonwa, U. E.; Nwakile, C. D.; Onochie, F. T. O. Formulation and Evaluation of Goat Fat and Shea Butter Based Lipospheres of Benzyl Penicillin. Int. J. Pharm. Sci. \& Res. 2012, 3, 1022-1027.

13. Majekodunmi, S. O.; Matthew, E. B. Evaluation of Goat Fat as Potential Co-Lubricant in Pharmaceutical Tablet Dosage Form. IOSR J. Pharm. 2014, 4, 01-09.

14. Momoh, M.; Attama, A. A.; Kunle, O. O. Formulation In Vitro and In Vivo Evaluation of SRMS-Based Heterolipid-Templated Homolipid Delivery System for Diclofenac Sodium. Drug Deliv. 2014, 23, 907-915.

15. Attama, A. A.; Nzekwe, I. T.; Adikwu, M. U.; Onugu, O.; Nnamani, P. O. The Use of Solid Self-Emulsifying Systems in the Delivery of Diclofenac Sodium. Int. J. Pharm. 2oo3, 262, 2328.

16. Attama, A. A.; Mpamaugo, V. E. Pharmacodynamics of Piroxicam from Self-Emulsifying 
Lipospheres Formulated with Homolipids Extracted from Capra hircus. Drug Deliv. 20o6, 13, 133-137.

17. Usha, S. B. M.; Kiranmai, M. I.; Indira, Y. 2012. Self-Emulsifying Tablets of Ibuprofen: Design, Optimization and Evaluation. Res. J. Pharm. Biol. Chem. Sci. 2012, 3, 0975-8585.

18. Obitte, N. C.; Ofokansi, K. C.; Nzekwe, I. T.; Esimone, C. O.; Okoye, I. E. Self-nanoemulsifying Drug Delivery Systems Based on Melon Oil and its Admixture with a Homolipid from Bos Indicus for the Delivery of Indomethacin. Trop. J. Pharm. Res. 2011, 10, 299-307.

19. Toth, L.; Muszbek, L.; Komaromi, I. Mechanism of the Irrevervisible Inhibition of Human Cyclooxygenase-1 by Aspirin as Predicted by QM/MM Calculations. J. Mol. Graph. Model. 2013, 40, 99-109.

20. Vonkeman, H. E.; Mart, A. F. J. Non-steroidal Anti-inflammatory Drugs: Adverse Effects and their Prevention. Semin Arthritis Rheum. 2010, 39, 294-312.

21. Aalykke, C.; Lauristen, K. Epidemiology of NSAID Related Gastroduodenal Mucosal Injury. Best Pract. Res. CL. GA. 2001, 15, 705-722.

22. British Pharmacopoeia. British Pharmacopoeia Office: MHRA, 151 Buckingham Palace road, London SW1W9SZ; 2013.

23. Adebayo, A. S.; Akala, E. O. Kinetics Model for the In Vitro Release of a Hydrophilic Drug (Amodiaquine) from Fat-Based Suppositories. Int. J. Arts Technol. 2005, 2, 1-11.

24. Setnikar, I.; Fontani F. Content Uniformity in Rectal Suppositories. J. Pharm. Sci. 1970, 59, 1319-1324.

25. Field, C. J.; Blewett, H. H.; Proctor, S.; Vine, D. Human health benefits of vaccenic acid. App. Physio. Nut. Metab. 2009, 34, 979-991.

26. Ofoefule, S. I.; Chukwu, A.; Nwankwo, C.; Orisakwe, O. E. In-Vitro Properties of Ciprofloxacin Suppositories Formulated with Glycerogelatin and Theobroma Oil Bases. Boll. Chim. Farm. 1998, 137, 341-344.

27. Taylor, O.; Igwilo, C. I.; Adeoye, D. I.; Awosika, O. O. In Vitro Release of Paracetamol from Various Suppository Formulations of Purified Shea Butter. J. Pharm. Sci. Pharm. Pract. 1993, 2, 93-99.

28. Sahoo, C. K.; Sudhakar, M.; Ramana, D. V; Satyanarayana, K. A Discussion on Quality Control of Suppositories. MJPMS. 2017, 6, 1618 .

29. Carter, S. J. Dispensing for Pharmaceutical Students. CBS Pub., Delhi, 1987; pp. 231-252. 